\title{
A CRITICAL ANALYSIS OF THE PREVALENCE AND NATURE OF EMPLOYEE ASSISTANCE PROGRAMMES IN THE EASTERN CAPE BUFFALO CITY MUNICIPAL AREA
}

\section{Thiloshni Govender, Lourie Terblanche}

\section{INTRODUCTION}

"Being a strong advocate of an EAP does not necessarily translate into the effective implementation and oversight of an EAP" (Burke \& Sharar, 2009:7) - this could be seen as a possible reason why some EAPs are more strongly aligned to certain standards or minimum requirements, as compared to other EAPs.

The rationale for the original study undertaken by one of the authors of this article was exactly to explore the way in which EAPs are designed, implemented and administered in order to benefit future programmes.

"Assistance to troubled employees in the Republic of South Africa (RSA) is nothing new. However, the concept of Employee Assistance Programmes (EAPs) in its traditional structured format is quite new [here]" (Terblanche, 1992:17). There has been significant development in the field of Employee Assistance in South Africa since this statement was made in 1992.

The development of EAPs in South Africa has been influenced by various professions, arose out of different organisational needs and occurs in varying forms and levels of sophistication depending on staffing, availability of resources and capacity within organisations. Whilst the predecessor of South African EAPs is largely American, in this country EAPs have taken on a unique shape and scope. South African EAPs have been influenced by our unique socioeconomic and political challenges mirrored in our workforces. Even the unique South African First World/Third World dichotomy seems mirrored in the development of EAPs with different levels of sophistication and form occurring in different parts of the country influenced by the availability of financial, human and technical resources.

In South Africa the last two decades of EAP development have been strongly influenced by transformation issues of the changing political climate, increased focus on managing the impact of disease, especially HIV and AIDS, occupational health and safety, organisational development and other issues outside of the traditional focus on psychosocial issues of the troubled employee.

Despite being around for almost three decades, there is limited information available on the implementation of the concept of EAP in South African workplaces. The principal researcher has been involved professionally in the field of Employee Assistance since 1996 and has been a witness to some of its evolution, growing complexity and potential to make a positive impact on individuals and organisations through the workplace relationships and dynamics. The motivation for this study came from an interest in gaining a deeper understanding of the concept and implementation of EAPs by organisations in the researcher's immediate working environment and circle of potential influence.

\section{LITERATURE REVIEW}

EAPs as they exist today are a result of decades of evolution. This evolution has been influenced by the history and dynamics of the organisations which house them and the occupational groups that have taken the responsibility for human service needs. In essence, 
according to Maynard (2004:36), employee assistance is "the application of knowledge about behavior and behavioral health to make accurate assessments, followed by appropriate action to improve the productivity and healthy functioning of the workplace".

According to Du Plessis (1991:35), Terblanche (1992:118-119) and Harper (2000:317-318), employee assistance services in South African workplaces can be traced as far back as the 1930s, with their roots in the field of occupational social work, which developed within the context of the welfare system and the apartheid system of government. EAP evolution was nurtured by champions and pioneer professionals from social work, human resources, and occupational health within the mining and private sector industries. EAP development was initially influenced by a paternalistic sense of "internal" social responsibility and later by management of poor performance, behaviour and health risk management as well as change management in times of societal and workplace transformation.

EAP development in the public sector started in 1995 with representation being made to the Public Service Commission regarding the introduction of EAP in the public service. The request included a definition of EAP and referred to BX111 of the Public Service Staff Code, which identifies a need for the provision of counselling and employee assistance so that every officer/employee performs optimally. The team making the representation saw the role of EAP as playing a crucial role in restoring normality in the departments by reducing labour turnover and facilitating change and adjustment to the transformation that was taking place as a result of socio-political changes.

In the Eastern Cape in 1996 the Office of the Premier established an EAP for the Provincial Administration, which was then decentralised to the individual departments. The development of EAP in the public sector has been compromised by resource and capacity challenges.

The definitions of EAP demonstrate its evolution in scope and range of services. The earlier definitions by Googins and Godfrey (1987:102) and Blum and Bennet (1990:143) see EAPs as a mechanism providing systematic means or policies and procedures focused on dealing with the impact of the troubled employees. Later definitions by Kurzman (1993:35) and EAPA (2003 e-member news) offer a broader scope and range of services including education and prevention, and for the first time EAP is cited as a resource utilising core technologies to enhance workplace effectiveness through prevention, identification and resolution of personal and productivity issues. Kurzman (1993:35) defines comprehensive EAPs as "free and confidential workplace entitlements that are voluntarily sponsored by employers or trade unions, jointly or both. In-house (internal) and contract (external) EAPs respond to the human service needs of workers and their families and to corresponding agendas of the work organisation. Under the overall direction of professional health or mental health staff, such EAPs address comprehensive current and prospective bio-psychosocial progress of education, prevention, assessment, treatment, case management and referral".

The models of EAP include, according to Phillips and Older (1988:133-135), Masi (2000:407), Myers (1984:82-83) and Cunningham (1994:22), mainly internal, external and blended models, with the latter being various configurations of the former two models. Fleisher and Kaplan (1988:31-34) offer factors that need to be considered when choosing an appropriate model and these include: size and distribution of workforce, mission, cultural climate, allocation of resources, target population, range of services, administrative considerations and funding sources. Given that workplaces are so unique, Smith (1988:10) suggests that because "not all EAP models are equally viable for any particular organisation, it is likely that whatever model 
emerges is the result of a dynamic combination of organisational size, complexity and resources as well as management philosophy, community resources and organisational history". The core technology of EAP, according to Herlihy (2002:12-13), represents the essential components of the employee assistance profession which combine to create a unique approach to addressing work organisation productivity issues. These core technologies include: consultation and training, problem identification and assessment, constructive confrontation, referral for diagnosis, treatment and assistance, consultation to work organisation, consultation with work organisation for health and evaluation. The core technology is currently being debated as being somewhat limited as far as proactive intervention is concerned and Bennet and Attridge (2008:4) feel that "preventive services for mental health, addictions, and workplace behavioral issues are now ready to be considered a core component of what EAPs do and how they are valued".

Bennet and Attridge (2008:6) proposed "evidence-based workplace prevention as a new core technology. They indicated that the EAP field could benefit from the addition of a new core technology that focuses on direct delivery of prevention services within the workplace which would include outreach, screening, assessment, awareness education and skills training for individuals and workplace cultures to help reduce risks and increase strengths. Inclusion of prevention as a new core technology and developing standards to benchmark practice and provide guidelines, in the same way as it does for the reactive direct services, could encourage EAP practice to implement proactive strategies, interventions and tools consciously and purposefully.

Standards for EAP practice were developed by EAPA-SA in 1999 and later revised in 2005. These 27 standards represent the benchmarks and guidelines for practice. According to the EAPA-SA Standards document, the standards are broadly categorised and include the following:

- Programme design: advisory/steering/consultative committee; needs assessment; service delivery models; pricing models;

- Implementation: policy; policy statement; implementation plan;

- Management and administration: staffing; EAP consultation and case management; confidentiality; record keeping; professional liability insurance; ethics;

- Direct services: trauma debriefing; crisis intervention; assessment and referral; short-term intervention; monitoring; follow up and aftercare; organisational consultation; training of managers, supervisors and union representatives; marketing;

- Networking: networking with internal organisational structures; networking with external community organisations and resources; networking with professional organisations; networking with external agencies;

- Evaluation: according to the writer, the Standards document lays out in detail what the crucial elements are in EAPs, but maintains a focus on dealing with the troubled employee. It remains limited in its outline of the proactive prevention and education elements of EAPs. The authors believe, from practice and observation, that prevention, education and awareness programmes form an essential part of EAP practice and need to be included in the core technology and Standards document as part of Direct Services.

From the review of the literature it can be seen from the history, definitions, models of service delivery, core technology and standards, EAPs have evolved in complexity from the early days 
of providing material aid and assistance to employees to becoming a fairly sophisticated professional field of practice, making it an effective resource for work organisations to manage employee and productivity issues, if implemented correctly.

\section{THE EMPIRICAL STUDY}

Against this background the authors hope to describe how EAPs have developed in the Eastern Cape Buffalo City Municipal Area (BCMA). This study sought to analyse the prevalence and nature of EAPs in work organisations employing a minimum of 200 people within BCMA to obtain reliable information on these programmes, so that implementation of employee assistance can be evaluated and improved. Burke and Sharar (2009:6) express the following opinion in this regard: "High EAP value is associated with efficient and effective vendor responsiveness, innovative approaches to meeting the needs of employers, and quantifying the results or outcomes of the services provided. Low value is associated with low utilisation, limited visibility, and minimal involvement with management or those responsible for EAP oversight".

It is therefore crucial also to obtain a view of the value being linked by users - which can to a large extent be predicted by the above realities.

This investigation provides a critical description of the implementation of EAPs in the BCMA with a view to establish prevalence, critically analyse the nature of EAPs and benchmark them against existing EAP standards.

The study is quantitative, exploratory and descriptive in nature as it sought to measure prevalence and to describe implementation in terms of form, shape, scope, staffing and services offered. These descriptive elements are benchmarked against the Standards for EAPs in South Africa, developed by the EAPA-SA, the official voice of the EAP profession in South Africa.

The study used a quantitative, descriptive (survey) design. The population was selected from the databases of the Border-Kei Chamber of Business and the Eastern Cape Provincial Administration, which together identified the appropriate respondent organisations from both the private and public sectors. There was no sampling done as there were 47 qualifying organisations, with 15 from the public sector and 32 and from the private sector. They were all formally approached to participate in the study, but since participation was voluntary only 30 responded positively.

The data-collection instrument was a structured questionnaire, which was piloted with two respondents, one from the private sector and one from the public sector. These respondents met the same requirements as the main group of respondents, namely being appointed in the position of EAP practitioner at the relevant organisation and government department. These two respondents were not included in the final survey. The final questionnaires were administered in groups and through individual interviews to individuals, responsible for Employee Assistance in their respective organisations. Thirty of the identified 52 organisations participated in the study. The responsible EAP practitioners in charge of the relevant EAP at the participating organisation, company or government department completed the questionnaires. 


\section{FINDINGS}

\section{The Buffalo City world of work}

The BCMA is a relatively small area, which includes the towns of East London, King Williams Town and Bisho. There are few organisations that have workforce more than 200 employees which was one of the criteria for inclusion in the original study. Bisho is the legislative capital city of the Eastern Cape Province and the centre for most government offices. The Provincial and District offices of most national and Provincial Government Departments are located in East London.

A total number of 30 questionnaires were successfully completed out of 47 respondents, which is a response rate of $64 \%$. The respondent profile included 12 public sector organisations and 18 from the private sector. The workforces varied in size, from 200 to 500, with 54\% having employed more than 500 people, and in geographical distribution across many worksites ranging from one to more than 30 .

\section{Prevalence of EAPs}

The prevalence of EAPs amongst respondent organisations was $77 \%$. The $23 \%$ who reported that they did not have an EAP were from the private sector; they varied in size between 200 and more than 500 employees and also in the number of worksites. The reason for their lack of an EAP was not explored in this study. The respondents who did not offer employee assistance services were not required to complete the remaining questions.

BCMA is a relatively small area, which has many small organisations. A connection needs to be made between the prevalence and the size of the respondents' workforce. As previously suggested by Fleisher and Kaplan (1988:31-34), size is a factor that affects an organisation's decision to offer employee assistance services. Other factors may include the fact that those employers do not have the financial and other resources to provide EAPs; they may believe that there are sufficient resources in the community to assist any troubled employees or they may not have bought into the concept of EAP. In the public sector the scenario is very different. With DPSA having given direction to government departments to implement employee assistance, the prevalence of EAP became a compliance issue.

\section{History of EAPs in BCMA}

Most of the EAPs in the survey were initiated after 1996, with the majority in the new millennium. The year 1996 has significance for the public sector, since this was the year that the DPSA, being that organ of state that provides direction to most public sector organisations, directed departments to provide employee assistance to improve work performance and service delivery. It was a critical period in the political history of South Africa as the new democratic government sought to meet its political mandate and demonstrate its ability to raise the quality of life of the previously disadvantaged by improved service delivery. EAPs became a compliance issue for departments and in the new millennium this concept grew in prevalence and sophistication.

The timing of post-1996 and new millennium EAPs may also be significant, with the increasing prevalence and awareness of the impact of the HIV and AIDS pandemic on society and on the workforce. Managing the impact of this pandemic provided a catalyst for EAPs as they strove to provide HIV and AIDS services within a climate of stigma and discrimination. HIV and AIDS have had a major impact on the South African workforce both in the public and private 
sectors and there has been considerable pressure on employers to provide care and support as well as to mitigate the impact of this pandemic.

International trends show that EAPs were largely initiated by the employer or by champions within the organisation, probably because of the internal social responsibility and legislative compliance concerns. According to Cagney (1999:65), there are programmes that have been initiated and are managed by unions, but on a national level there seem to be no known employee assistance programmes administered and funded by unions (Terblanche, 2009:218). According to the results, BCMA organisations seem to be in line with the international trends. The vast majority of 21 respondents confirmed that their EAPs were initiated by management.

\section{NATURE OF EAPS IN BCMA}

\section{EAP Model}

Sixty-six percent of the EAPs were combined or blended models. Combination models are becoming increasingly popular as organisations seek EAP solutions to best fit their unique needs and available resources. The size and complexity of the respondent organisations of BCMA vary considerably and require EAPs that can meet the demands of the client system, whilst making optimal use of both internal and external resources. The combined model also allows the EAP to select and change the services offered according to employee and organisational needs.

A significant percentage (30\%) of respondents, in line with what Phillips and Older (1988:133135) indicated, have fully internal models for the following probable reasons: respondents may:

- want full ownership of the programme because of their special needs or organisational culture;

- want an EAP that has knowledge of the organisation and its culture;

- desire better communication and more credibility;

- want to provide multiple roles and assessments of organisational systems.

This number of $30 \%$ fully internal programmes compares favourably with the number of $20 \%$ internal programmes, as noted by Herlihy and Attridge (2005:67), despite a difference in the time of the research being carried out.

\section{EAP funding}

The majority of respondents $(61 \%)$ indicated that they have a designated budget for EAP, positively demonstrating management support and investment in the EAP. It is also an indication that EAPs are becoming autonomous business units within the organisations they serve and EAP professionals are being given more financial responsibility in bidding for, managing and reporting on their own budget. Those respondents that did not have a designated budget explained that the service was funded by the parent or other programmes, such as the Human Resource Management/Development, Occupational Health, HIV/AIDS or is sourced as and when needed. They also make use of community resources and medical aid benefits.

\section{EAP positioning}

There was a variation in the location of EAPs within organisational structures which correlates with the variation in the occupational fields that historically championed EAP. These included human resources, corporate services and occupational health, but all these units can be broadly 
categorised as "employee services" as expounded in Thomlison's (1983:13) systems theory as a sub-system of the employer system.

\section{EAP staffing}

TABLE 1

CORRELATION OF EAP AGE, SIZE AND DISTRIBUTION OF WORKFORCE AND MODEL WITH STAFFING.

\begin{tabular}{|c|c|c|c|c|c|c|c|c|}
\hline \multirow[b]{2}{*}{ 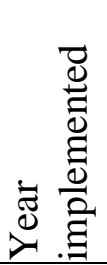 } & \multirow[b]{2}{*}{ 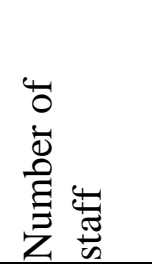 } & \multirow[b]{2}{*}{ 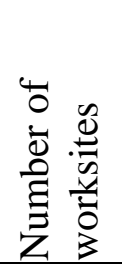 } & \multicolumn{3}{|c|}{ Model of EAP } & \multicolumn{3}{|c|}{ Number of EAP staff } \\
\hline & & & 胥 & 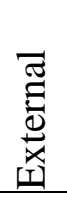 & 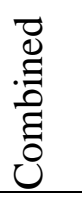 & 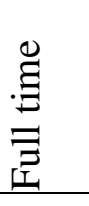 & 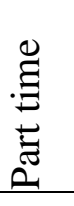 & 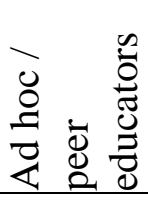 \\
\hline 2005 & $>500$ & 1 & $*$ & & & 1 & . & - \\
\hline 1999 & $>500$ & 12 & $*$ & & & 1 & - & - \\
\hline 2004 & $>500$ & $>26$ & $*$ & & & 2 & - & - \\
\hline 2003 & $>500$ & 97 & $*$ & & & 11 & - & 62 \\
\hline 2003 & $>500$ & 48 & * & & & 1 & 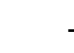 & - \\
\hline 2004 & $>500$ & $>7$ & $*$ & & & 37 & - & 52 \\
\hline - & $>500$ & 2 & - & & & - & 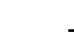 & - \\
\hline 2001 & $>500$ & 2 & - & & & 1 & . & 4 \\
\hline- & $>500$ & 27 & - & & & 1 & . & - \\
\hline 1997 & $>500$ & 3 & - & & & - & . & 2 \\
\hline 2002 & $>500$ & - & - & & & - & 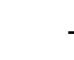 & 1 \\
\hline- & $>500$ & $>7$ & - & & & 2 & . & 15 \\
\hline 2005 & $>500$ & $>6$ & - & & & 3 & . & 12 \\
\hline 2004 & $>500$ & 55 & - & & & 3 & - & - \\
\hline- & $400-500$ & 1 & - & & & - & 3 & 10 \\
\hline 2003 & $400-500$ & 6 & - & . & & 2 & . & - \\
\hline- & $400-500$ & 7 & - & . & & 6 & - & - \\
\hline 1998 & $300-399$ & 2 & - & . & & - & 3 & - \\
\hline- & $300-399$ & - & * & & & 1 & . & - \\
\hline- & $200-299$ & 1 & - & & & - & . & 1 \\
\hline 1999 & $200-299$ & 3 & - & & & 2 & - & - \\
\hline- & 200-299 & 1 & - & & & - & . & 1 \\
\hline 2001 & 200-299 & - & - & & & - & . & $>5$ \\
\hline
\end{tabular}

Ninety-one percent of the respondents have designated EAP staff, which showed a significant shift away from having "champions" to having dedicated employees to perform the function. Employee assistance has evolved considerably from the fellowship of recovering alcoholic co- 
workers and "welfare secretaries" of the early 1900s to professional and specialised services from multiple disciplines in the new millennium.

On closer examination, however, the designated staff do not all have a full-time EAP function. Sixty-five percent of respondents have EAP personnel on a full-time basis and $47 \%$ have both full-time and ad hoc staff, which is a positive reflection that there is more commitment to and support for programme services, and is also an indication that EAPs have become more sophisticated. Eight percent of respondents have personnel with part-time EAP functions and $26 \%$ with ad hoc/add-on EAP functions only. This is an indication that organisations still have a long way to go to optimise the potential of EAPs to add value to their organisations. It is the researcher's view that the EAP has the potential to make a substantive impact on the organisation, if it has dedicated and competent personnel.

Staffing of EAPs, which is a critical factor in programme design and implementation, seems incidental rather than carefully considered. A bird's eye view of the correlation between the age and model of the EAP as well as the size and geographic distribution of the workforce in relation to the staffing reveals that there is no consistency in the way EAPs are staffed. EAP age and model, as well as workforce size and distribution, should have influenced the staffing so that it would be adequate and appropriate to programming needs, especially for the internal models.

EAP age and model as well as size and geographic distribution are usually determinants of the staffing of EAPs. It is often assumed that the newer programmes, as indicated by year that the EAP started, may have fewer staff because the programme design and infrastructure are still being finalised. This is clearly not the case with the respondents. It is evident that there is no consistency on the EAP: workforce ratios as compared to the size of the workforce and geographical location. The issue of EAP staffing ratio is critical to internal EAPs, as the EAP practitioners may be expected to provide a comprehensive service, but may not be able to cope with the need, thereby compromising the credibility of the programme and its potential to add value. With the combination models the situation is more flexible, because the needed services will be contracted, whilst the EAP personnel monitor the contracts.

The respondent organisations had an expected spread of EAP personnel through the different levels within the organisational structure. It is to be expected that the highest percentage $(62 \%)$ would come from the operational levels, as this is the point of service delivery. A significantly lower percentage $(14 \%)$ of respondents had personnel at the senior management level, which is where the strategic decisions are made regarding the running of the organisation. Positioning the EAP at senior management level allows for the programme to participate and contribute significantly to the business goals of the organisation, especially in terms of managing the risks that impact on services. The results seem to indicate that many EAPs have not reached that point of strategic influence and value, possibly because of being newly implemented or the organisational structure may not allow for representation on senior management level.

\section{PROFESSIONAL AND OCCUPATIONAL BACKGROUND OF EAP PERSONNEL}

The results reflect the variety of fields that EAP has evolved from, with social work; human resources and occupational health being the most common. With EAP evolving further into more holistic employee wellness programmes, it would be in the interest of the organisations to have access to a multidisciplinary team of professionals. If this variety of professionals could be reflected in each EAP, the organisation would be able to access a broader range of services such as health as well as behaviour risk management. 


\section{BENEFICIARIES OF EAP SERVICES}

This is dependent on the individual organisation: its values in respect of internal social responsibility, its conceptualisation of the employee system, and the resources available for service delivery. Of significance in the results is that $42 \%$ of the respondents extend services to the family members of employees - these organisations recognise the employee system in its entirety and that families impact on the wellbeing of individual employees and so impact on work performance. Therefore it is prudent to extend services to families in the interests of employee wellness and productivity. Resources allocated to services to the families in these organisations may be viewed as an investment in improving organisational productivity.

\section{RANGE OF EAP SERVICES AS PER CORE TECHNOLOGY}

Most respondents implement the full range of EAP services as outlined by the Core Technology in EAPA-SA Standards (2005:7-8). The variance in the extent of implementation comes in the specific core technologies related to case management of troubled employees, indicated in problem assessment, short-term intervention, monitoring of referrals, follow up and aftercare, which are most prevalent. These specific services have been the priorities and the core of EAPs since the early days of implementation. Implementation of this full range of EAP services indicates a satisfactory level of sophistication, and programme evolution in the respondent organisations. Evaluation of the impact of EAP seems not to be as well developed as the other existing technology, possibly because respondents could be experiencing difficulty in quantitatively measuring the impact, or are in the early stages of programme development, so it may be premature to engage in evaluation exercises.

\section{EAP PREVENTION AND OTHER PROGRAMMES}

The vast majority of respondents $(87 \%)$ indicated that prevention programmes were a part of their EAP services. The other services offered by EAPs not covered by the EAPA-SA 2005 Standards include:

- prevention;

- wellness days;

- calendar events (e.g. World TB Day, International Day against drug abuse);

- education programmes;

- sport and recreation;

- HIV and AIDS;

- occupational health and safety;

- ill health and incapacity management; and

- job accommodation process.

These results are clearly evidence that the scope of EAP has broadened to include a variety of activities deemed necessary by the respondent organisations in implementing the concept of EAP or complementing it. This reflects an emerging trend that is transforming EAPs into proactive employee wellness programmes. In the United States of America, as explained by Du Plessis (1991:210), the early occupational alcoholism programmes of the 1940s evolved in the 1970 s into the "broad-brush" EAP, as it became recognised that the full range of personal problems also negatively impacted on job performance and needed to be managed. 
In the authors' experience, working in the field on EAP, it was observed that most EAP practitioners were involved in services that were proactive and preventative in nature. However, this type of service has not been the focus area within the EAP field and as such has not been adequately represented in the core technology and standards for practice. It may be that EAP is being broadened at both a conceptual and implementation level to be more proactive and holistic as organisations seek to consciously reduce the impact of a broad range of bio-psycho-social risk factors on employee and organisational productivity. This broader focus may also result from the influence of the many disciplines actively involved in employee assistance.

\section{BENCHMARKING BCMA EAPS AGAINST EAPA-SA STANDARDS}

\section{Programme design standards}

FIGURE 1

APPLICATION OF EAPA-SA PROGRAM DESIGN STANDARDS (n=23)

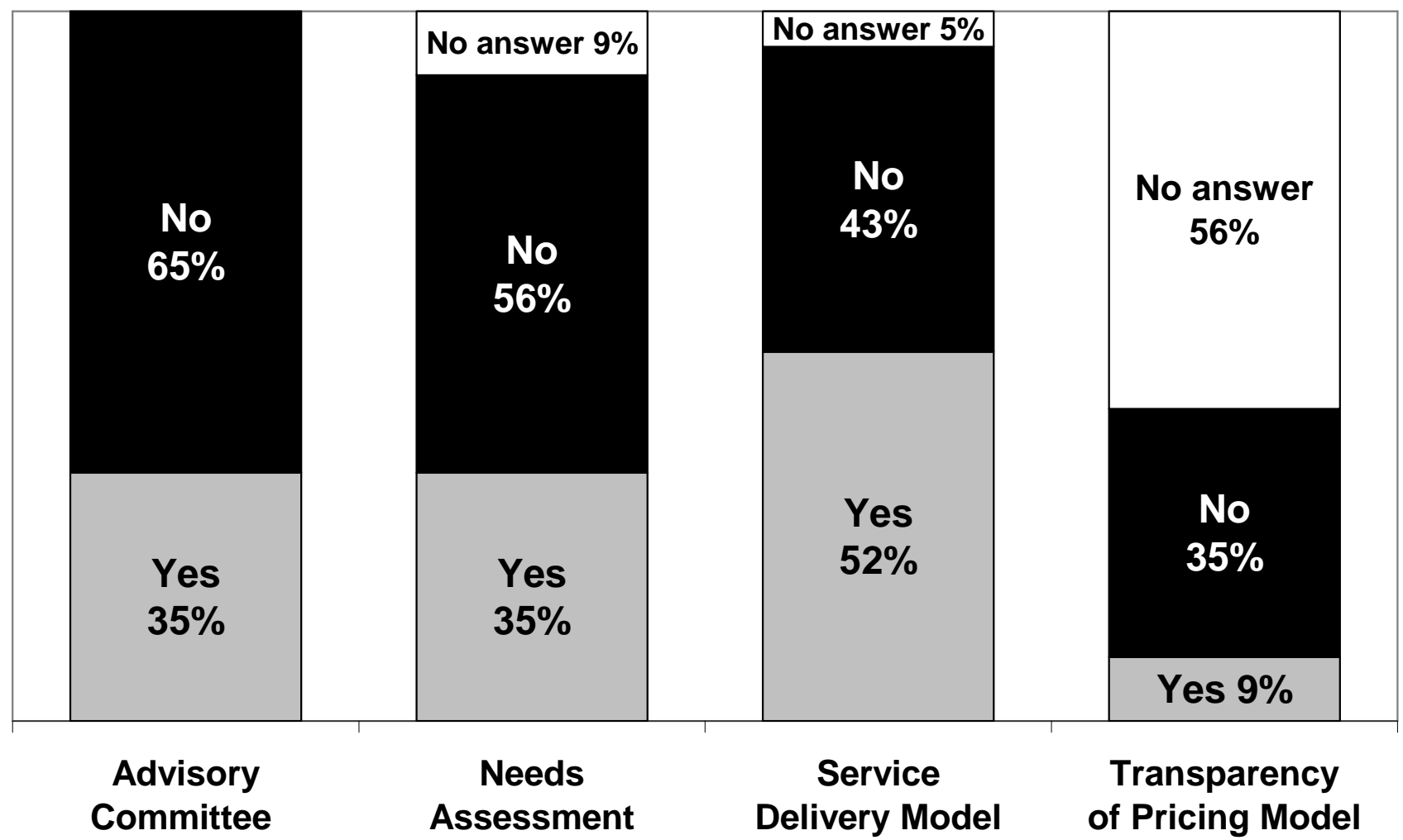

The respondent EAPs reflect poorly against these standards, indicating that these EAPs have either not found them important to implement or have been unable to do so.

According to Googins and Godfrey (1987:164-165) the advisory committee provides a critical support base for the EAP, assisting in design, implementation, promotion and evaluation. This anomaly leaves the question: how do these programmes implement the needed services? It could be that the support and involvement of relevant stakeholders has been obtained but not formalised into a structure, or that the implementers of the EAP have proceeded on their own, which could present some problems with legitimacy at some point in the future of these programmes. It may also be possible that EAP managers have been unable to establish and maintain functional advisory committees because there is limited or no commitment, ownership and buy-in from key stakeholders or that programmes are new and still establishing credibility within the organisation, with the main drivers being the champions or EAP personnel. 
Needs assessment has been identified as being core to EAP design because it enables EAP personnel to develop an understanding of the client population and informs the services that will be rendered. It is usually carried out at the beginning of EAP implementation and at regular intervals after that. The poor level of implementation of this standard could be the result of limited capacity and resources to conduct a needs assessment or because the organisation may be pressured by external factors, such as national policy, to comply with certain areas of EAP implementation and may base services on perceived need rather than conducted research. Organisations that do not conduct needs assessment in any form carry the risk of rendering services to which the client population may not attach priority, thereby compromising the value and credibility of the EAP in that organisation.

Only $52 \%$ of respondents acknowledge a specific service delivery model and a significant $43 \%$ do not. It is possible that the latter EAPs may be in the early stages of development and may not have finalised a service delivery model or that EAP personnel may not have the knowledge or capacity to link their services to a specific model. The combined service delivery models may be difficult to define as services may be dynamic and still evolving.

The standard on pricing models is a new addition to the Standards document of 1999 and end users may not be familiar with it. Pricing should be negotiated, transparent and agreed on by all EAP stakeholders. It is more possible, however, that those EAPs may be from internal and combined models where pricing models are not an identified issue. Specific EAP services may be outsourced when required for limited periods and transparency issues of pricing may not be considered. The significant percentage of respondents that could not answer may be an indication that they are not aware of pricing issues and were therefore unable to answer, or that pricing issues are dealt with at higher levels within the organisation and they may not have been involved.

Almost all respondents were affirmative about EAP policy and significant majorities (66\%) also had a policy statement and were operating from an implementation plan, demonstrating that EAPs operate within a policy framework and that planning for service delivery does take place. However, there is a significant percentage of respondents that did not answer or had a negative response on having an implementation plan. The respondents with no EAP implementation plan were all from the private sector, where the EAP was provided on a parttime basis by the occupational health professionals. These professionals provided some case management services to troubled employees, but this was not part of their core function. These organisations all had an EAP policy, but it seems that they did not find it necessary to have implementation plans to guide EAP service delivery. 


\section{Implementation standards}

FIGURE 2

APPLICATION OF EAPA-SA IMPLEMENTATION STANDARDS (n=23)

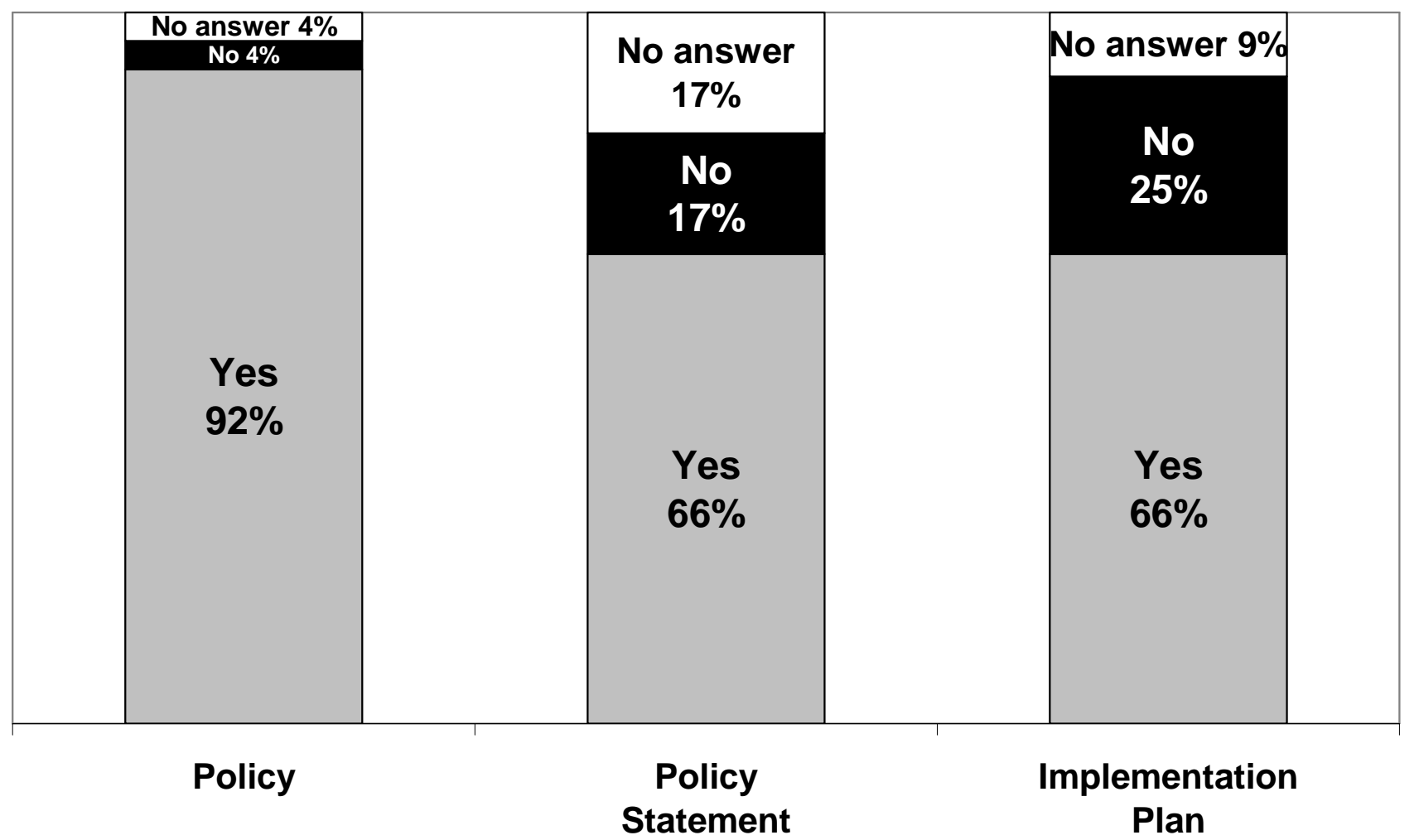

Appropriate ratios of EAP personnel to size of workforce have historically been a very subjective and sensitive issue. The results reflect a significant majority (74\%) who perceive an inappropriate number of EAP staff. This could be because organisations have limited resources, or to the EAP being new. It may also be that organisations initially employ one person to start the EAP and increase the number of staff, if deemed necessary. Many EAPs are seriously understaffed and subjected to limited resources and functional infrastructure.

The issue of appropriate qualifications is also a subjective and sensitive issue in the EAP field, especially because of the variety of disciplines that have historically rendered services. The results show a majority of respondents $(61 \%)$ that perceive their EAP staff to be appropriately qualified, but there is a significant percentage (39\%) that gave a negative or no response. Perceptions are subjective to the understanding of the respondent of the term "appropriate", which may differ considerably from organisation to organisation. Some organisations that outsource their EAP functions may find it appropriate to have EAP staff that can manage a contract and not necessarily render services themselves. The EAPA-SA Standards document (2005:9) itself differentiates between an EAP "professional" and "practitioner". The appropriateness of the qualification of EAP personnel is specific to their identified job responsibilities and it may differ amongst respondents. 
Management and administration standards

FIGURE 3

APPLICATION OF EAPA-SA MANAGEMENT AND ADMINISTRATION STANDARDS

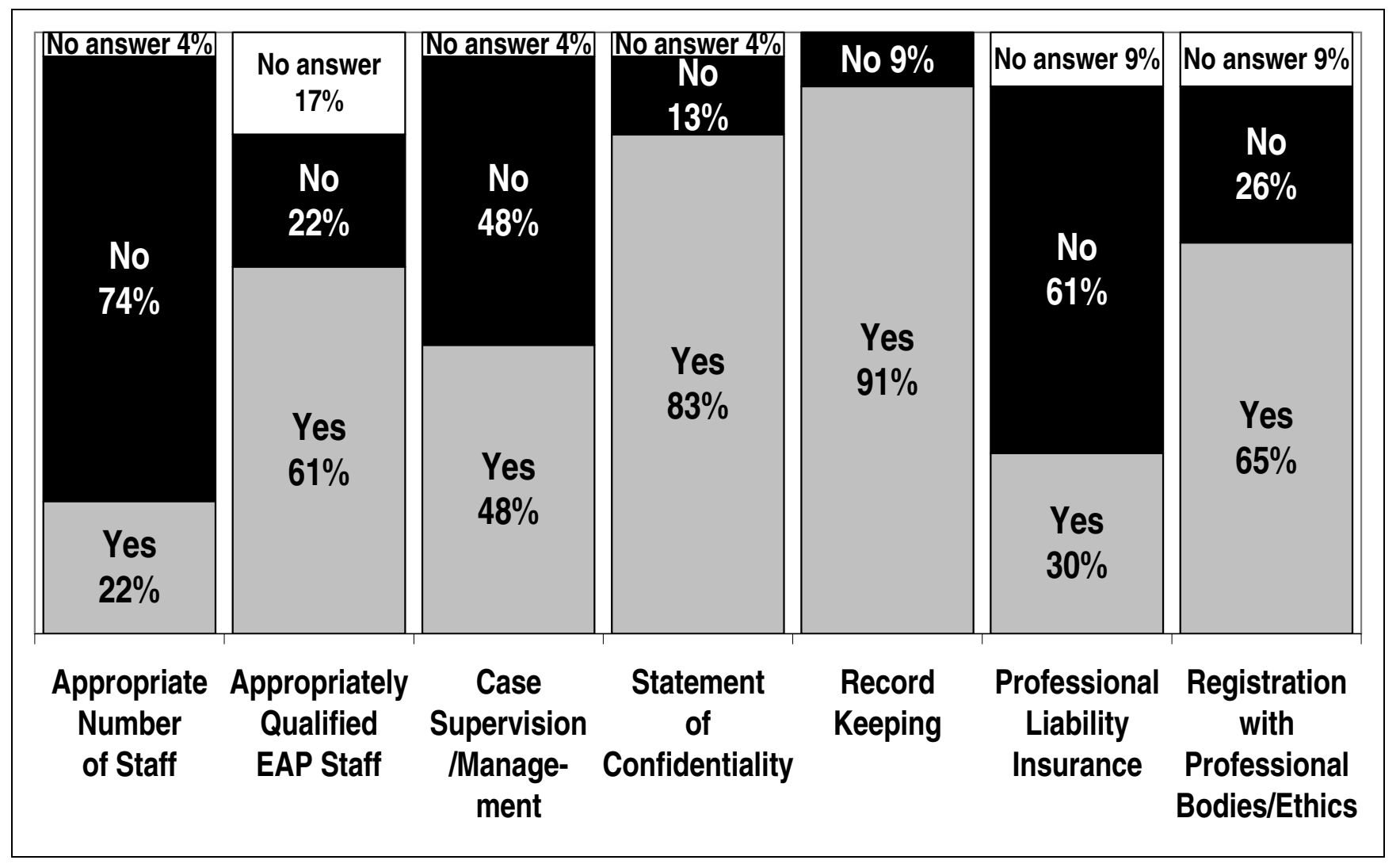

The respondents seem split equally on the issue of case management/supervision, which is an essential element when dealing with employees and their personal challenges. Case management/supervision provides professional support, development and guidance to practitioners in their handling of clients, protecting both the EAP practitioner and the client. The absence of this among $48 \%$ of respondents indicates dangerous ground ethically. The potential risks of misconduct and unethical practice become exceptionally high when there is no supervision, especially in view of the capacity limitations that many practitioners experience. The EAP field has many practitioners who are not appropriately qualified to render specialised or professional services, not are they registered with any statutory bodies that regulate conduct.

Confidentiality is the cornerstone of an EAP - it is a critical principle without which the programme would suffer from poor credibility and utilisation. A significant majority of respondents (83\%) were affirmative about having a statement of confidentiality, which indicates acknowledgement of and respect for this critical principle. Those respondents that gave a negative answer may be at the initial stages of programme development and may not have a written statement of confidentiality yet.

Record keeping is also a critical element of EAP management and administration and the majority of respondents $(91 \%)$ were affirmative in their response. Keeping records is essential to monitoring and evaluation of EAP as it provides for establishing baseline information, 
reporting progress and evaluating programme implementation and effectiveness. Format and details of records, however, were not explored as part of this study, which made it impossible to comment on standardised record keeping.

With regard to professional liability insurance, a significant majority $(61 \%)$ responded negatively, indicating either a risk area or that the organisation itself may take responsibility for any liability arising from service provision. It is the opinion of the researcher that the area of liability may not be taken seriously by organisational personnel and management in South African EAPs. This may be so because we may have a client population who are not aware of their rights in terms of misconduct or even the standard of services they are entitled to receive.

Registration with professional bodies seems to be a matter taken seriously by a small majority of respondents $(65 \%)$; however, there is a significant percentage that do not. This situation could be the result of the EAP services not being recognised by many as professional in nature, because the EAP may be offered on an ad hoc or part-time basis by practitioners who may not be part of any profession. Those who are professionally trained, may be registered with their respective statutory bodies, since there is no such option exclusively available in the EAP field.

\section{Direct service standards}

FIGURE 4

APPLICATION OF EAPA-SA DIRECT SERVICES STANDARDS

$(n=23)$

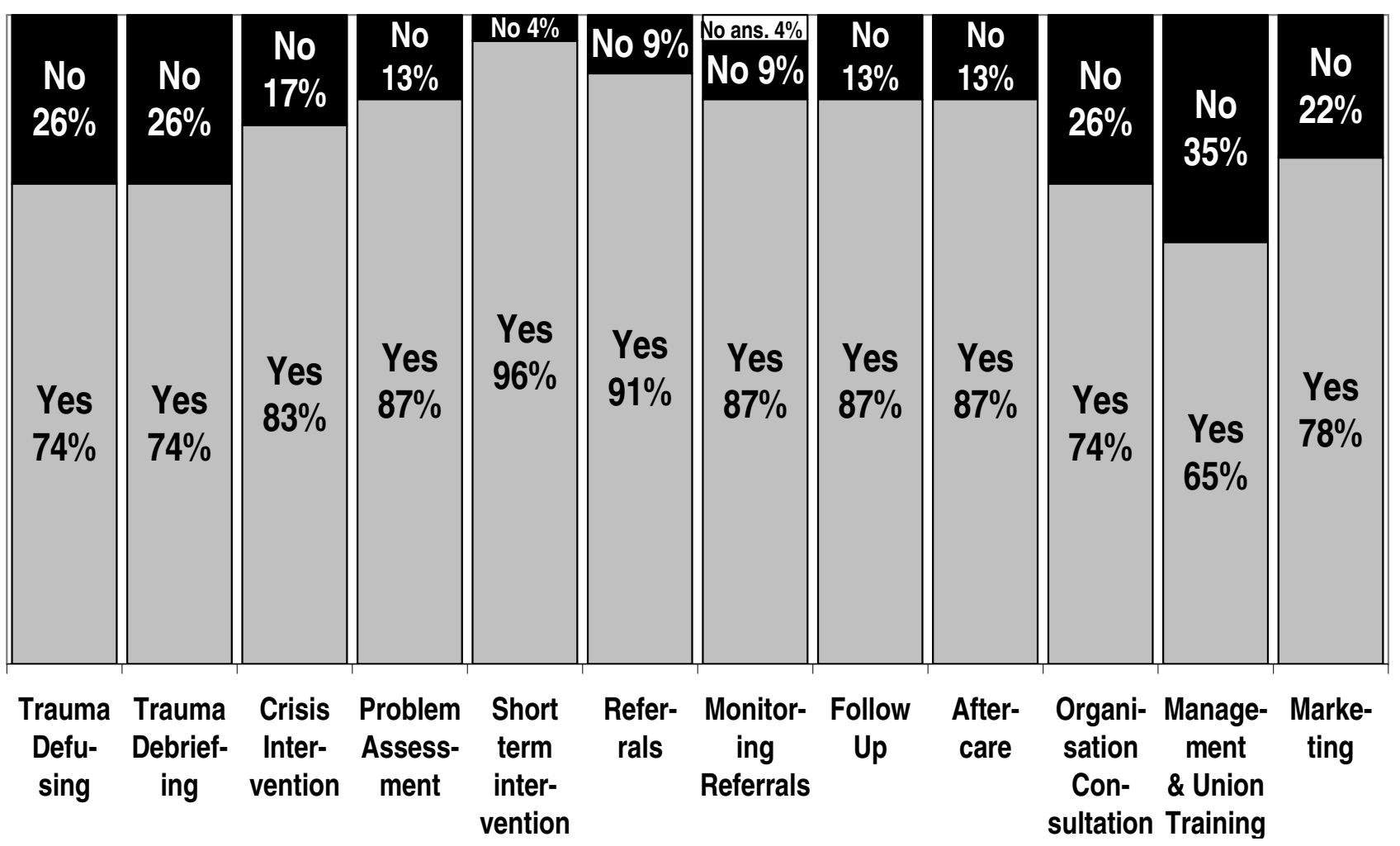

It is clear from the results that in terms of direct services, there is a high level of implementation (65\% to $96 \%$ ). These are the services that form EAP transactions and they are most valued by the end users of EAP. Trauma care services, crisis intervention and case management of troubled employees have traditionally been the priority of EAP implementation as they directly benefit the employee, management and union systems within the organisation. 
The high levels of affirmative responses in short-term intervention and referrals are an indication that practitioners are using external resources in their case management. Short-term intervention methodology is common to EAPs because the value added for both employers and employees is embedded in the restoration of the functionality and required level of productivity of the troubled employee as quickly as possible. Referral to external resources is also an indicator of the combined models being used by most respondent organisations.

Organisational consultation was offered by $74 \%$ of respondents, and management and union training by $65 \%$ indicates growing sophistication in employee assistance programming, thus demonstrating a move beyond just managing the troubled employee to developing management and union competence to deal with broader people management.

\section{Networking and evaluation standards}

\section{FIGURE 5 \\ APPLICATION OF EAPA-SA NETWORKING AND EVALUATION STANDARDS} $(n=23)$

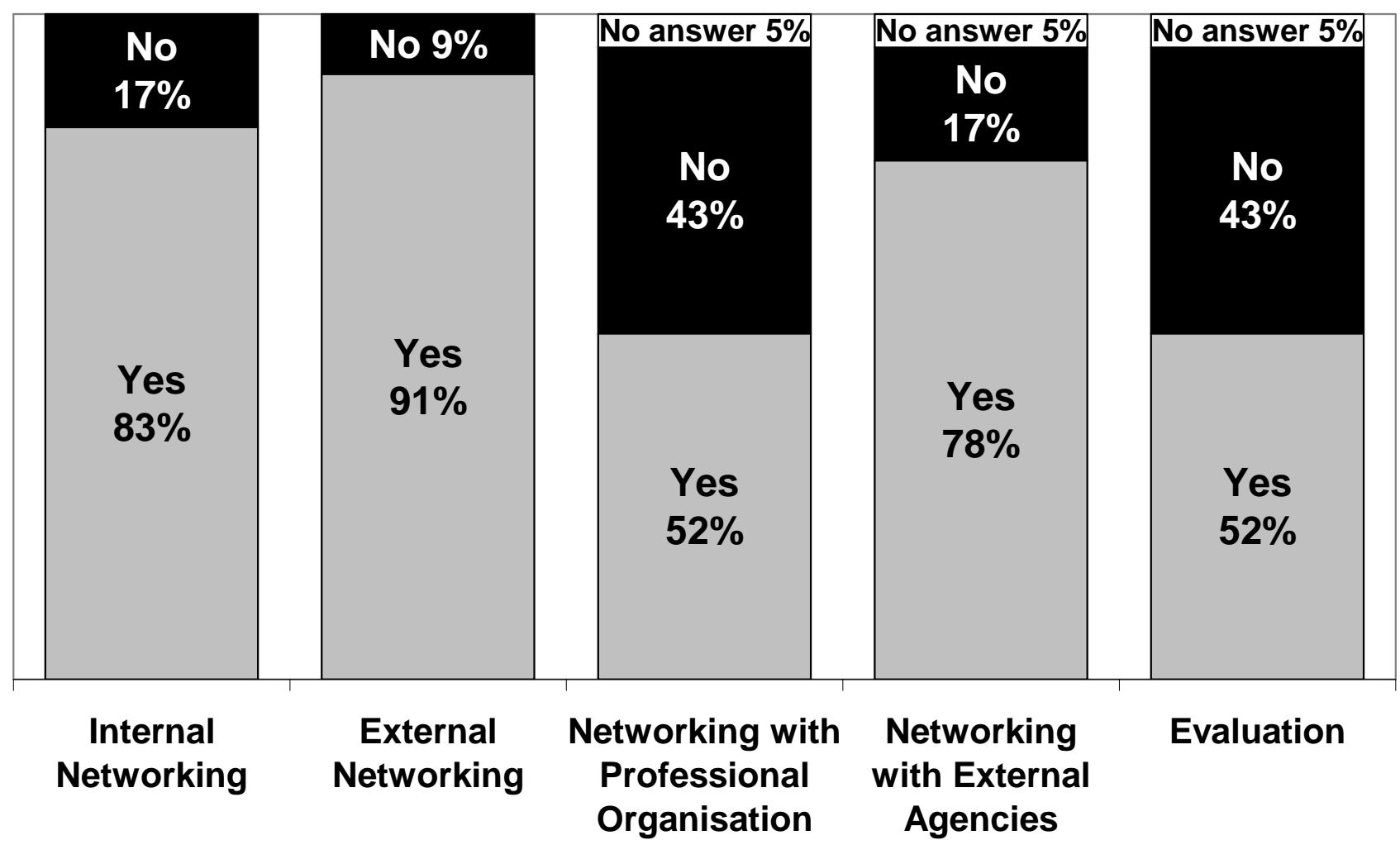

In terms of networking with internal and external resources and agencies, the results indicate a significantly high level of implementation (78\% to $91 \%$ ). This would mean that these EAPs are making efforts to:

- enhance two-way communication with resources as well as functional integration into the culture and operations of the organisation, as suggested by Googins and Godfrey (1987:125);

- contribute positively to the dynamics of the workplace in assisting business units to understand each other better as well as to identify and deal with larger systemic problems;

- make efficient use of organisational resources and reduce the cost of certain EAP services; 
- fill service-delivery gaps by exploring and utilising external skills and other resources. This is a major advantage for combination models as they can enhance EAP capacity by cosourcing resources on a needs basis;

- remain updated on practice frameworks and the latest information available in the field of EAP.

The high percentage confirming active networking is seen as a positive regarding contribution towards chances of successful operational EAPs. Fauria (2009:13) confirms in this regard: "Through closer working relationships with employers, EAP professionals can re-establish EAP Core Technology principles that distinguish employee assistance from integrated behavioral health care".

Implementation of networking with professional bodies, however, is lower (52\%) than the previous networking standards, which could be because some EAPs are newly implemented and have newly appointed staff. EAP practitioners may be members of professional bodies, but their interaction and therefore communication may be limited if they are not actively involved.

The results indicate a significantly low level of implementation (52\%) of evaluation as a standard, which should be an issue of concern. Evaluation is critical to EAPs, even if they have been newly implemented. Baseline information on EAP performance indicators is essential to determine impact and value added of programmes. This information can be gained from organisational records and reports, and be determined by research methods at the onset. EAPs risk losing credibility and may not be aware of service delivery gaps, if they do not have efficient evaluation systems.

In summary and ranked from the most to the least implemented are the direct service standards, which were consistently high amongst the vast majority of respondents. These standards revolve mainly around managing the troubled employee. Less common but still implemented by a majority between $60 \%$ to $80 \%$ percent of respondents are the standards that cover some of the programming and other direct service issues such as planning, staffing, training and consultation, marketing and networking. A possible reason for this could be that when services are initiated, the focus is on delivering the most needed direct services, which once implemented expands to other issues. Of least consistency in implementation are the programme design and implementation standards. There is substantial variance between these and the direct service standards. This is an anomaly, because these standards provide the framework of EAP services to the end users and it does not make sense for them to be omitted, especially where direct services are in place. Just as the foundation is laid before a structure is built, so too the programme design and implementation standards should be in place before direct services are established.

The EAPA-SA Standards were developed to provide benchmarks for EAP practice and they seem to form a logical pattern of programme development. EAPA-SA (2005:7) acknowledges that that the standards will ensure quality EAPs, but there is room for customisation according to the unique culture and operation of organisations. In BCMA the EAPs seem to vary significantly in the way they have developed by seemingly implementing those standards deemed most necessary and then moving to the foundational and more sophisticated elements of programming. 


\section{KEY RECOMMENDATIONS}

The employment sector, including organised labour and business management forums, need to promote the concept of EAP to their membership, facilitate implementation and support EAP development within member organisations.

Companies that have successfully implemented EAP should mentor and coach other companies in establishing such programmes.

Organised labour needs to play a more significant role, not just in initiating but also in advocating for, designing, supporting, managing and administering employee assistance. Given the general adversarial relationship between employers and organised labour, this may result in a higher utilisation of such programmes, because employees generally trust their union more than their employer.

The employee assistance advisory committees provide an ideal platform for equal participation in programming issues by unions, management and EAP personnel - organisations should ensure that there is a functional EAP advisory committee.

Organisations need to reconsider or give more careful consideration to the choice of EAP model. Factors to be considered could include:

- the nature and size of workforce;

- geographical spread of the workforce;

- organisational culture;

- available human and other resources both internal and external;

- employee preferences (they should be consulted);

- target population;

- location; and

- range of services to be offered.

The following aspects also need to be taken into account.

- Organisations or those initiating EAPs need to be encouraged and assisted to conduct research-based organisational profiling and needs assessment to inform their choice of model. These organisations can contract a specialist service provider to conduct such research and assist with EAP design, if they do not have the internal capacity to do so.

- EAPA-SA needs to provide more detailed guidance on programme design issues, specifically to redesign the standards to expand on benchmarks within the framework of the respective models. For example, there could be specific benchmarks within each type of model focusing on what would be adequate in terms of resourcing and administrative concerns. Alternatively a detailed implementation guideline could be developed for the respective models to supplement the benchmarks contained in the EAPA-SA Standards.

- Employers need to invest in EAP through adequate resourcing in order for the programme to reach optimal potential and provide significant return on investment.

- Organisations should give more careful consideration to the staffing of EAPs, especially with the internal models. Factors such as size and geographical distribution of the workforce, target population and range of EAP services should inform the process of staffing. 
- Organisations should conduct research with EAP personnel, beneficiaries of EAP services and critical stakeholders from management to scientifically evaluate the impact of staffing on the effectiveness of their EAP.

- EAP standards need to be more specific regarding what entails "appropriate" and "adequate" staffing for the respective EAP models as these are very subjective terms. These will establish benchmarks within specific frameworks that will guide organisations implementing EAPs.

- EAPA-SA needs to be more specific in terms of staffing ratios for EAPs, obviously within the framework of specific factors. Since it is a benchmark, organisations will still have the final decision on the matter.

- Managers responsible for EAP should explore other options for funding programmes for example:

- co-sourcing through an option for employees to make a monthly contribution towards the EAP, which can be effected as a deduction from their salaries - the amount needs to be determined according to affordability and would be a bargaining issue for negotiation between employer and employees. It would mean that employees also contribute to a programme that they benefit from;

- allocating a proportion of the salary bill for EAP for example: $0.5 \%$ of total salary bill using the same principle as the skills levy.

- EAP personnel should actively bid for a designated budget and be responsible for financial management and reporting. This financial reporting should be linked to EAP performance and indicators that demonstrate value to the organisation.

- EAPA-SA should develop a system of accrediting EAPs that have achieved preset benchmarks as an incentive for organisations striving for excellence.

- EAPs should strive for representation at senior management level so that organisational consultation and advice on human capital issues can take place more effectively.

- EAPs should ensure that their target population has access to multidisciplinary services, even if these services are contracted on a need basis.

- The respective professions involved in employee assistance need to adopt a collaborative rather than a competitive approach to ensure that the beneficiary of the services receives the best possible service.

- EAPA-SA should develop standard designations or job titles for EAP personnel linked to specific job functions. These designations should be based on an accreditation system and include a job description.

- Organisations should be sensitised on the benefits of providing EAP services to the immediate families of employees as well, in order to maximise the overall value and altruism of the programme.

- EAP professional development needs to increase focus on the core technology and related competencies beyond "managing the troubled employee". These competencies should include: training, facilitation, presentation, marketing and research to enable practitioners to apply the core technology confidently. 
- EAP training may be another way for EAP personnel to engage stakeholders by providing them with detailed information on EAP practice and give them an opportunity to introspect on their support and involvement.

- EAP training institutions need to increase focus on programme design issues and equip EAP practitioners with knowledge and skills in this area.

- The educational institutions providing undergraduate training to the various professions involved in EAP need to include EAP-specific theoretical and practical training modules to expose these professionals to the employee assistance programme field. This will assist in increasing the pool of appropriately qualified and experienced EAP professionals available for recruitment.

- EAP personnel need to ensure that they are involved in continuous EAP-specific professional development to build on their competency.

- Research needs to explore proactive and holistic interventions in the EAP field to establish the prevalence, nature of services, impact and role in EAP practice.

- EAPA-SA should review the core technology and the direct service standards to uplift proactive and holistic intervention as a separate or special area of practice.

- EAPs should conduct evaluation research at the beginning of the EAP - when conducting needs assessment and organisational profiling - to establish baseline indicators for later evaluation of impact, and partnering with stakeholders in measuring the impact of the EAP on the organisation and the employees. Such research will provide an opportunity for the stakeholders to become directly involved with the EAP, in "reviewing" the programme model and addressing the areas of weakness. This participation can be formalised as a task for the advisory committee.

- Organisations initiating EAPs need to conduct research to develop a profile of the needs and risks facing the organisation. This profile should establish baseline data on variables indicating risk areas for the organisation, e.g. sick leave rate, employee satisfaction, etc. These variables could then be measured at different intervals to determine EAP impact on and value to the organisation. This process will also assist in quantifying the return on investment in EAP.

- EAPA-SA could develop generic tools or instruments that can be used to assist practitioners in conducting evaluation research.

- EAPA-SA should develop a system of accreditation for EAP practitioners so that they can measure their performance and be recognised for their competence in defined areas of practice.

- Sector Education Training Authorities (SETAs) should develop a Recognition of Prior Learning (RPL) programme to accredit those practitioners who have been active in EAP practice and who have learnt on the job. This process would also assist the professionalising the field of EAP in South Africa.

- Training institutions, EAPA-SA and EAP managers should strengthen EAP personnel competencies in the service areas of organisational consultation and EAP training and research methodology, so that they can optimise the value of their programmes to their organisations. 


\section{CONCLUSION}

Benchmarked against the EAPA-SA Standards, the EAPs in BCMA had satisfactory implementation levels, demonstrating that EAPs have evolved and grown in sophistication. However, there is clearly more focus on EAP direct service delivery rather than programme design and management activities. This would imply that EAP services seem to be fortuitous rather than carefully designed, and that the EAPs evolved and took shape according to need for those who championed it and as time progressed.

The EAPA-SA Standards for practice have also developed alongside EAPs so it can be suggested that the programmes initiated prior to the year 2000 evolved out of need and available resources rather than according to purposeful design. Programmes implemented in the new millennium have the benefit of established guidelines for practice and may also bring new information into the field, especially around programming issues. It needs to be noted, however, that there has been limited impact of the development of EAP standards on older existing EAPs. The level of awareness of EAPA-SA Standards and core technology seems limited and needs to be addressed possibly by means of the following:

- Active promotion of the EAPA-SA Standards within the field of EAP and to business management forums and other similar platforms;

- An accreditation programme for both EAP practitioners and organisations implementing EAP;

- Performance-based incentives for practitioners and organisations.

This may increase consistency in implementation and raise the level EAP practice in South Africa.

\section{REFERENCES}

BENNET, J.B. \& ATTRIDGE, M. 2008. Adding prevention to the EAP core technology. Journal of Employee Assistance, 38(4):4-6.

BLUM, T.C. \& BENNET, N. 1009. Employee assistance programs: utilization and referral data, performance management and prevention concepts. In: ROMAN, P.M. Alcohol problem intervention in the workplace: employee assistance programs and strategic alternatives. New York: Quorum Books.

BURKE, J. \& SHARAR, D.A. 2009. Do "free" EAPs offer discernible value? Journal of Employee Assistance, 39(3):6-9.

CAGNEY, T. 1999. Models of service delivery. In: OHER, J.M. (ed) The employee assistance handbook. New York: Wiley \& Sons.

CUNNINGHAM, G. 1994. Effective employee assistance programs, counselors and managers. California: Sage Publications.

DU PLESSIS, A. 1991. A society in transition: EAPs in South Africa. EAP Digest, March/April:35-62.

DU PLESSIS, A. 1991. Occupational social work practice. In: McKENDRICK, B.W., DROWER, S.J., DU PLESSIS, A., HOFFMAN, W.C. \& LIVINGSTONE, B.J. Social work in action. Pretoria: HAUM Tertiary.

EMPLOYEEE ASSISTANCE PROFESSIONALS ASSOCIATION SOUTH AFRICA CHAPTER. 2005. Standards for employee assistance programmes in South Africa. Johannesburg: EAPA-SA. 
FAURIA, T.M. 2009. Commodity or craft: the choice is ours. Journal of Employee Assistance, 39(3):13-15.

FLEISHER, D. \& KAPLAN, B.H. 1988. Employee assistance counselling typologies. In: GOULD, G.M. \& SMITH, M.L. Social work in the workplace: practice and principles. New York: Springer Publishing Company.

GOOGINS, B. \& GODFREY, J. 1987. Occupational social work. New Jersey: Prentice Hall, Inc.

GOVENDER, T. 2009. A critical analysis of the prevalence and nature of employee assistance programmes in the Eastern Cape Buffalo City Municipal Area. Pretoria: University of Pretoria. (Unpublished MA Dissertation)

HARPER, T. 2000. South Africa. In: MASI, D.A. International employee assistance anthology $\left(2^{\text {nd }} \mathrm{ed}\right)$. Washington: Dallen Inc.

HERLIHY, P.A. 2002. Employee assistance and work/life core technologies. EAPA Exchange, May/June:10-13.

HERLIHY, P.A. \& ATTRIDGE, M. 2005. Research on the integration of employee assistance, work-life and wellness services: past, present and future. In: ATTRIDGE, M., HERLIHY, P.A. \& MAIDEN, R.P. The integration of employee assistance, work/life and wellness services. New York: Haworth Press: 67-93.

KURZMAN, P.A. 1993. Employee assistance programs: towards a comprehensive service model. In: KURZMAN, P.A. \& AKABAS, S.H. Work and well-being: the occupational social work advantage. Washington D.C.: NASW Press: 26-45.

MASI, D.A. 2000. International employee assistance anthology $\left(2^{\text {nd }}\right.$ ed $)$. Washington: Dallen Inc.

MAYNARD, J. 2004. Maintaining our heart. Journal of Employee Assistance, 34(2):36.

MYERS, D.W. 1984. Establishing and building employee assistance programs. London: Quorum Books.

PHILLIPS, D.A. \& OLDER, H.J. 1988. Models of service delivery. In: DICKMAN, F., CHALLENGER, B.R., EMENER, W.G. \& HUTCHISON, W.S. Employee assistance programs. Illinois: Charles $C$ Thomas Publishers.

SMITH, M.L. 1988. Social work in the workplace: an overview. In: GOULD, G.M. \& SMITH, M.L. Social work in the workplace: practice and principles. New York: Springer Publishing Company.

TERBLANCHE, L.S. 1992. The state of the art of EAPs in South Africa: a critical analysis. In: MAIDEN, R.P. (ed) Employee assistance programs in South Africa. New York: The Haworth Press.

TERBLANCHE, L.S. 2009. Labour welfare in South Africa. Journal of Workplace Behavioral Health, 24(1-2):205-220.

THOMLISON, R.J. 1983. Perspectives on industrial social work practice. Canada: Family Service.

Ms Thiloshni Govender, registered student for the programme MSW (Employee Assistance Programmes); Prof Lourie Terblanche, Department of Social Work and Criminology, University of Pretoria, Pretoria, South Africa. 